\title{
Myocarditis and colchicine: a new perspective from cardiac MRI
}

\author{
Daniel Morgenstern ${ }^{*}$, John Lisko², Nicholas C Boniface², Brandon M Mikolich', J Ronald Mikolich²,1 \\ From 19th Annual SCMR Scientific Sessions \\ Los Angeles, CA, USA. 27-30 January 2016
}

\section{Background}

Because of anatomic proximity, myocarditis is often associated with pericarditis. Although randomized trials have not delineated a successful evidence-based therapy for myocarditis, there is evidence of considerable benefit in treating pericarditis with a regimen of colchicine and a non-steroidal anti-inflammatory drug (NSAID). Cardiac MRI (CMR) is capable of detecting both myocarditis and pericarditis using T2 weighted pulse sequences and delayed enhancement imaging with gadolinium. This study was designed to assess the effect of a colchicine/NSAID treatment regimen for myocarditis identified by CMR.

\section{Methods}

An institutional CMR database was queried for all patients with pericarditis who had associated myocarditis. Those patients with at least 1 follow-up CMR study to assess response to therapy with a colchicine/NSAID regimen constituted the study population. The follow-up CMR studies were categorized and tabulated as resolved, partially resolved or no improvement with respect to myocarditis, based on consensus of 2 experienced CMR interpreters.

\section{Results}

Forty-eight patients in the database were found to have myocarditis/myo-pericarditis by CMR and at least 1

\section{Myocarditis: Response to Colchicine}

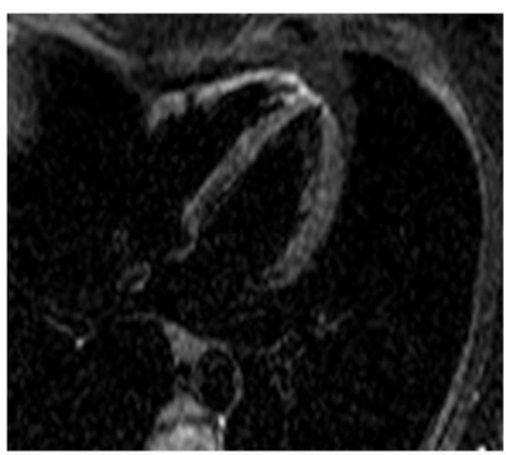

$10-28-14$

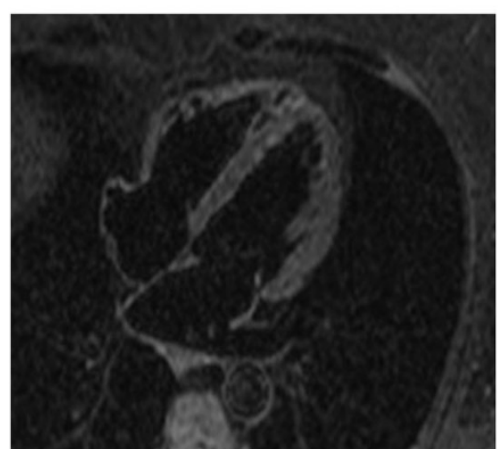

02-23-15

\section{T2 STIR 4 chamber view}

Figure 1 Myocarditis response to colchicine therapy.

${ }^{1}$ Sharon Regional Health System, Hermitage, PA, USA

Full list of author information is available at the end of the article

(c) 2016 Morgenstern et al. This is an Open Access article distributed under the terms of the Creative Commons Attribution License (http://creativecommons.org/licenses/by/4.0), which permits unrestricted use, distribution, and reproduction in any medium, provided the original work is properly cited. The Creative Commons Public Domain Dedication waiver (http://creativecommons.org/ publicdomain/zero/1.0/) applies to the data made available in this article, unless otherwise stated. 
follow-up CMR study. Twenty-seven of these patients received colchicine and 17(63\%) showed complete resolution of myocarditis on their last CMR study. Of the 21 patients who did not receive colchicine, only $8(38 \%)$ had resolution of myocarditis by CMR study.

\section{Conclusions}

Randomized trials for treatment of myocarditis were done prior to the availability of CMR imaging for this diagnosis, and were mainly comprised of severe cases presenting as heart failure. Myocarditis appears more readily diagnosed with CMR, especially in its less fulminant presentations. This study suggests that myocarditis, documented by CMR, is responsive to colchicine, with rates of successful therapy similar to those of published reports of colchicine for pericarditis. These data also suggest that CMR imaging should be considered in any future randomized trials of myocarditis therapy, including colchicine.

\section{Authors' details}

Sharon Regional Health System, Hermitage, PA, USA. ${ }^{2}$ Northeast Ohio

Medical University, Rootstown, OH, USA.

Published: 27 January 2016

doi:10.1186/1532-429X-18-S1-0100

Cite this article as: Morgenstern et al: Myocarditis and colchicine: a new perspective from cardiac MRI. Journal of Cardiovascular Magnetic

Resonance 2016 18(Suppl 1):0100.
Submit your next manuscript to BioMed Central and take full advantage of:

- Convenient online submission

- Thorough peer review

- No space constraints or color figure charges

- Immediate publication on acceptance

- Inclusion in PubMed, CAS, Scopus and Google Scholar

- Research which is freely available for redistribution

Submit your manuscript at www.biomedcentral.com/submit 